\title{
Evaluasi Pasca Pembangunan Proyek Infra-struktur : Sebuah Kebutuhan Penguatan Kapasitas Birokrat Perencana di Pemerintah Daerah
}

\author{
Budisantoso Wirjodirdjo $^{1^{*}}$, Diesta Iva Maftuhah ${ }^{1}$, Iffan Maflahah ${ }^{1,2}$ \\ 1 Institut Teknologi Sepuluh Nopember \\ Kampus ITS Sukolilo, Jalan Raya ITS Surabaya 60111 Jawa Timur \\ ${ }^{2}$ Universitas Trunojoyo Madura \\ Jalan Raya Telang No 02 Kamal Bangkalan 69162 Jawa Timur
}

*Email: budisantoso.wirjodirdjo@gmail.com

Naskah diterima 11 Desember 2020, Revisi 15 Maret 2021, Terbit 29 April 2021

\begin{abstract}
DOI: doi.org/10.21107/pamator.v14i1.9257
Abstract

Infrastructure development in an area before construction requires preparation and comprehensive initial studies and is an obligation for infrastructure project owners. Likewise, infrastructure development work is completed and operated, post-development evaluation is still needed to avoid unexpected impacts from infrastructure development. It has not been taken into account in the feasibility study. The regions' readiness and role are expected because the areas where the infrastructure is located have an interest and are the areas that are directly affected. However, post-development evaluation of infrastructure is often not carried out properly due to the limited capacity of regional human resources, especially planning bureaucrats in planning infrastructure development and then carrying out post-development evaluations of the infrastructure in their area. Local governments need to initiate capacity building activities for planning bureaucrats and related agencies so that each bureaucrat has a systemic thinking foundation in his work. The second level, local governments cannot work alone to improve the quality of their human resources. Local governments need to greet the nearest tertiary institution with various expertise and contribute this expertise to planning bureaucrats and related technical agencies. Besides, the level II regional government also needs to collaborate with the central government to provide expert assistance regarding post-infrastructure development evaluation.
\end{abstract}

Key words: infra-structure project, strengthening the capacity, regional government

\section{PENDAHULUAN}

Pemerintah pusat yang berkomitmen untuk meningkatkan jumlah berbagai infrastruktur mempunyai tujuan agar perekonomian nasional berkembang lebih cepat karena dukungan infra struktur yang semakin memadai. Sejalan dengan program pemerintah pusat tersebut sejak 6 tahun yang lalu panjang infra struktur salah satunya adalah jalan Tol bertambah dan di pulau Jawa sendiri telah tersambung jalan Tol dari kota Merak sampai dengan Probolinggo dan selanjutnya dalam pelaksanaan di perpanjang sampai dengan kota Banyuwangi. Di luar pulau Jawa pun pembangunan jalan Tol terus berlangsung. Kemudahan-kemudahan banyak diperoleh oleh daerah-daerah yang dilalui prasarana tersebut. Diantaranya adalah kemudahan akses untuk menjual nilai tambah daerah ke daerah-daerah lain yang membutuhkan secara cepat. Jarak antara kota sebagai pasar dan desa sebagai produsen tidak menjadi kendala yang berarti lagi.

Pemerintah pusat tentu saja dalam program peningkatan kualitas dan kuantitas infrastruktur tidak terbatas hanya pada jalan Tol, tetapi juga pelabuhan bandara, rel kereta api dan lain-lain karena infrastruktur tersebut akan meningkat daya saing Indonesia menjadi semakin tinggi dibandingkan dengan negara-negara tetangga lainnya. Demikian pula dengan ketersediaan infrastruktur yang lengkap maka akan mengundang investor untuk berinvestasi di Indonesia dan menciptakan lapangan kerja. Atas dasar pemikiran tersebut diatas pembangunan infra struktur menjadi prioritas pemerintah dalam mendukung pertumbuhan ekonomi dan peningkatan sumberdaya manusia Indonesia melalui pendidikan. 
Pembangunan infrastruktur disuatu daerah sebelum membutuhkan persiapan dan studi awal yang komprehensif dan merupakan kewajiban bagi pemilik proyek infrastruktur. Persiapan dan studi tersebut meliputi perencanaan fisik, evaluasi ekonomi dan lingkungan sebagai dasar keputusan pembangunan dan kelayakannya. Setelah pekerjaan pembangunan infrastruktur usai dan dioperasikan, evaluasi pasca pembangunan masih diperlukan untuk menghindari dampak-dampak yang tidak diharapkan dari pembangunan infratruktur dan belum diperhitungkan didalam studi kelayakan.

Pemerintah Daerah sering dihadapkan adanya permasalahan-permasalahan pasca pembangunan infrastruktur yang pada awal perencanaan tidak pernah diperhitungkan. Hal ini dapat mengurangi kemanfaatan infrastruktur yang telah dibangun. Kesiapan dan peran daerah sangat diharapkan karena daerah dimana infrastruktur tersebut berada berkepentingan dan merupakan daerah yang terdampak langsung. Namun demikian evaluasi pasca pembangunan infrastruktur sering tidak dilakukan sebagaimana mestinya karena keterbatasan kapasitas sumberdaya manusia daerah, khususnya perangkat birokrat perencanaan dalam hal melakukan perencanaan pembangunan infrastruktur dan selanjutnya melaksanakan evaluasi pasca pembangunan infrastruktur tersebut didaerahnya.

Dari kajian awal setelah tim mengadakan explorasi permasalahan-permasalahan yang dihadapi oleh beberapa Pemerintah Daerah tingkat II, diperoleh kesimpulan bahwa perangkat birokrat perlu ditingkatkan kapasitasnya didalam mengemban tugastugas perencanaan, koordinasi dan evaluasi atas seluruh kegiatan pembangunan dan pengembangan daerahnya. Evaluasi pasca pembangunan proyek infrastruktur merupakan salah satu pengetahuan dasar yang seharusnya dimiliki oleh para birokrat perencana di tingkat pemerintah daerah tingkat II untuk dapat melakukan kegiatan tersebut setelah proyek diserahkan kepada pemerintah daerah untuk dioptimalkan pemanfaatannya. Mengapa pemerintah daerah tingkat II yang menjadi sasaran, tentunya mempunyai argumentasi kuat yaitu: pemerintah daerah tingkat II kabupaten kota memiliki autoritas otonomi didaerahnya untuk melakukan penguatan kapasitas sumberdaya manusia daerah, khususnya perangkat birokrat perencanaan dalam hal melakukan perencanaan pembangunan infrastruktur dan selanjutnya melaksanakan evaluasi pasca pembangunan infrastruktur tersebut didaerahnya.

\section{Pentingnya evaluasi pasca pembangunan infrastruktur}

Terdapatnya beberapa kasus terkait tidak atau belum dilaksanakannya evaluasi infrastruktur pasca pembangunan lebih dikarena banyak proyek-proyek infrastruktur yang dibiayai oleh pemerintah pusat dan keberadaannya ada di daerah tingkat II. Proyek infrastruktur setelah selesai dibangun dan di operasikan, pemerintah daerah tingka II dimana infrastruktur tersebut berada tidak mampu untuk melaksanakan evaluasi. Tidak adanya evaluasi inilah yang menjadi salah satu sebab optimalisasi infrastruktur tersebut tidak dapat dilakukan. Lebih jauh dampak negatif dari pembangunan infrastruktur yang mungkin timbul dan belum diperhitungkan ketika fase perencanaan proyek infra struktur sulit dieliminasi. Salah satunya adalah terkait pembagunaan infrastruktur jalan Tol yang diinisiasi oleh pemerintah pusat dan melalui daerah-daerah tingkat II.

Pembangunan jalan Tol antara Cikampek dan kota Bandung tahun 2005, telah memperlancar arus manusia dan barang. Waktu tempuh menjadi separoh dari waktu sebelum dibangunnya jalan Tol. Sebagian lalu lintas barang dan manusia beralih dari jalan nasional ke jalan Tol. Situasi jalan nasional menjadi menarik dicermati dikarenakan setelah infrastruktur jalan Tol dioperasikan terjadi pengurangan asset ekonomi dan sosial masyarakat disepanjang jalan yang tergantikan oleh jalan Tol. Berbagai aktivitas perekonomian yang berskala kecil dan menengah yang selama ini hidup dan tumbuh kembang disepanjang jalan nasional mengalami penyurutan dengan dioperasikan jalan Tol. Berbagai restoran dan warung yang menjajakan produk-produk pertanian dan industri kerajinan daerah setempat berkurang pembelinya. Disadari bahwa masyarakat yang berkegiatan di sektor ini adalah masuk 
kategori rentan. Hal ini disadari setelah beberapa waktu pengoperasiaan jalan Tol. Pemerintah perlu memfasilitasi kelompok masyarakat ini untuk bisa akses dan terlibat didalam bagian jalan Tol, dengan memberikan penyuluhan kepada masyarakat disepanjang jalan nasional terdampak oleh beroperasinya jalan Tol. Dengan demikian masyarakat terdampak tersebut dapat berkegiatan di simpul-simpul "rest-area" yang terdapat disepanjang jalan Tol. Alih profesi dan menyiapkan masyarakat terdampak dari pembangunan jalan Tol perlu di siapkan oleh pemerintah daerah tingkat II sehingga partisipasi masyarakat dalam kehidupan ekonomi dan sosial tetap berjalan dan bahkan meningkat lebih baik. Dampak sosial kemasyarakatan juga dirasakan dengan terbelahnya suatu komunitas dalam suatu daerah dikarenakan oleh keberadaan jalan Tol. Suatu komunitas yang pada awalnya tidak terkendala oleh didalam keseharian berkehidupan sosial, dengan adanya jalan Tol mereka memiliki kategori baru masyarakat sebelah kiri dan masyarakat sebelah kanan jalan Tol, meskipun mereka dalam satu wilayah administrasi desa yang sama.

Contoh diatas tampak jelah menggambarkan bahwa evaluasi pasca pembangunan infrastruktur merupakan kegiatan yang tidak dapat diabaikan dalam usaha mengoptimalkan kemanfaatan sebuah infra struktur bagi kamaslahatan seluruh masyarakat dari berbagai strata ekonomi sosial yang ada disekitarnya. Namun hal ini tidak mudah untuk dijalankan mengingat masih lemahnya sumberdaya birokrat perencana dan dinas-dinas teknis terkait di pemerintahan daerah tingkat II. Penguatan kapasitas para birokrat perencana dan dinasdinas teknis terkait dirasakan urgent dan menjadi syarat penting bagi pemerintah daerah tingkat II untuk melakukan evaluasi pasca pembangunan infra struktur. Pemerintah daerah tingkat II harus mampu menjalin kerjasama dengan berbagai pihak terkait dengan hal tersebut, antara lain: perguruan tinggi terdekat yang mempunyai keahlian dalam bidang tata cara evaluasi pasca pembangunan atau pemerintah daerah lain yang telah mempunyai pengalaman melakukan kegiatan tersebut untuk berbagi best practice, dan pengalaman. Disamping itu kerjasama pengembangan sumberdaya manusia daerah perlu secara intens dilakukan oleh pemerintah daerah. Pemerintah daerah menitipkan kepada pemerintah pusat dalam pengembangan sumberdaya manusia.

\section{Paradigma Berpikir Sistim dalam evaluasi pasca pembangunan infrastruktur}

Keberadaan sebuah fasilitas infrastruktur dapat dipastikan akan mempunyai implikasi dan kemanfaatan luas dan tekait dengan sektor-sektor lain. Demikian pula sebuah infrastruktur tidak hanya menghasilkan kemanfaatan namun juga ada dampakdampak lain yang tidak diharapkan pada awal perencanaan. Dampak terhadap lingkungan hidup, kemacetan, pengurangan terhadap lahan produktip dan lain-lain yang pada prinsipnya semua dapat diperhitungkan.

Evaluasi pasca pembangunan infrastruktur adalah untuk mengkonfirmasi apakah dampak-dampak tersebut terjadi dan apakah dirasakan perlu adanya penanganan segera. Berpikir Sistem sangat diperlukan didalam evaluasi pasca pembangunan infrastruktur. Dengan berpikir sistem kita melihat keberadaan infrastruktur yang telah dibangun merupakan sebuah entitas infra struktur terkait dengan entitas-entitas lainnya yang saling berkaitan dan pengaruh mempengaruhi.

Permasalahan yang terjadi pada satu entitas bisa jadi akibat entitas yang lain demikian sebaliknnya. Oleh karenanya bagaimana mengelola entitas infrastruktur dalam satu daerah yang sama perlu sudut pandang sistemik dan menyeluruh. Sudut pandang satu disiplin ilmu pengetahuan tidak lagi digunakan tetapi sudut pandang multidisplin merupakan keharusan. Kerjasama diantara para expert dari berbagai bidang ilmu pengetahuan didasarkan atas semangat team work yang kuat.

Penyelesaian permasalahan yang didasar atas kerjasama team work merupakan penyelesaian masalah berdasarkan kearifan ilmu pengetahuan. Hal ini dirasakan sangat penting mengingat keberadaan infrastruktur tidak lepas dari ilmu pengetahuan dan teknologi. IImu pengetahuan dan teknologi itu sendiri bersifat netral. Kemanfaatan 
infrastruktur akan diperoleh bergantung kepada bagaimana manusia menggunakan infrastruktur tersebut. Pemanfaatan yang didasarkan pada kepentingan masyarakat banyak akan menjadi sebuah pemanfaatan yang berkearifan. Sebaliknya pemanfaatan infrastruktur yang didasarkan kepada ego sektoral, akan dirasakan mengurangi kemanfaatan infrastruktur itu sendiri, dan bahkan dapat menimbulkan bencana kemanusiaan akibat dari pembangunan infrastruktur yang dilakukan tanpa melihat permasalahan infrastruktur sebagai entitas sistemik.

Pemahaman sistemik dan berpikir sistemik sangat mendasar diperlukan oleh para birokrat perencana dan dinas-dinas teknis terkait di pemerintahan daerah Tingkat II. Dengan harapan para birokrat dapat bekerjasama, melepas ego sektoral yang selama ini mereka tekuni. Kerjasama lintas dinas lebih dipentingkan untuk menghasilkan sebuah kinerja perencanaan, pelaksanaan dan pengawasan yang efektip dan terukur kemanfaatannya bagi seluruh pihak-pihak yang berkepentingan terhadap keberadaan infrastruktur didaerah tersebut.

\section{Team work dalam perencanaan, pelaksanaan, pengawasan dan evaluasi pembangunan infrastruktur.}

Pembangunan infrastruktur melibatkan berbagi disiplin keahlian di setiap fasenya. Namun demikian tidak dimaksudkan setiap fase perencanaan, pelaksanaan dan pengawasan menjadi milik disiplin keilmuan tertentu, misalnya: keteknikan, ekonomi atau social. Setiap fase pembangunan infrastruktur, berbagai disiplin keilmuan sudah harus dilibatkan untuk berkontribusi di masing-masing fase dengan proporsi yang berbeda-beda. Sekecil apapun kontribusi yang diberikan, kontribusi tersebut penting dan tidak boleh diabaikan didalam kontek berpikir sistem. Disisi yang lain setiap disiplin keilmuan telah concern sejak awal dimulai dari perencanaan sampai dengan pengawasan dan evaluasi. Masing-masing pihak dapat belajar cara berpikir dari berbagai disiplin keilmuan yang terlibat didalam pembangunan infrastruktur. Menimbang-nimbang prioritas pilihan didalam menjawab permasalan pembangunan infrastruktur. Setiap keputusan atas pilihan merupakan keputusan team work.

Setiap fase pembangunan infrastruktur memiliki team leader yang berbeda-beda, dipilih sesuai dengan keahlian yang dibutuhkan pada setiap fase. Tetapi perlu diperhatikan setiap team leader yang dipilih seharusnya telah terlibat didalam fase sebelumnya. Dengan demikian team leader akan dengan mudah memahami permasalahan yang care over dan belum terpecahkan. Prinsip kesinambungan pola pikir perlu dijaga sedemikian agar tujuan dan target waktu penyelesaian pembangunan infrastruktur tidak mudah berubah. Demikian pula team leader sebelumnya harus tetap menjadi anggota team work sehingga dapat dimanfaatkan pula sebagai nara sumber dan membantu bila ada permasalahanpermasalahan pembangunan infrastruktur.

Kesadaran terhadap bekerja dalam team work dan bekerja secara multidisplin merupakan langkah awal dari penguatan kapasitas para birokrat perencana dan dinasdinas terkait dengan pembangunan infrastruktur. Untuk tahapan selanjutnya pembekalan terkait dengan teknik-teknik serta instrument metodologi lebih mudah diberikan apabila kesadaran dari team work dan berpikir sistem telah dipahami secara benar dan mampu merasakan bahwa bekerja dalam team work lebih ringan dibandingkan dengan bekerja dalam lingkup terbatas. Bekerja dalam lingkup terbatas akan melahirkan sikap miopi didalam memecahkan permasalahan pembangunan infrastruktur. Pelatihan bekerja dalam team work melalui simulasi juga merupakan terobosan yang efektip dalam membentuk kesadaran para birokrat perencana dan dinas-dinas teknis terkait. Dengan demikian masing-masing individu yang terlibat didalam team work dapat merasakan kemanfaatan yang lebih tinggi dibandinkan dengan cara kerja sebelumnya.

\section{KESIMPULAN}

Evaluasi

pasca pembangunan infrastruktur dirasakam belum cukup bila hanya dilakukan pada tahapan perencanaan, pelaksanaan, pengawasan. Evaluasi pasca selesainya pembangunan infrastruktur perlu dilakukan dalam usaha mengurangi dampak- 
dampak negatif terkait dengan keberadaan infrastruktur baru tersebut. Pemikiran sektoral didalam melihat keberadaan infra struktur juga harus sudah ditinggalkan. Hal inilah yang memicu adanya sebuah kebutuhan baru didalam melihat keberadaan infrastruktur, yaitu melihat permasalahanpermasalah infra struktur sebagai permasalahan sistemik. Paradigma berpikir sistem sebagai sebuah pendekatan pemecahan permasalahan harus segera disosialisasikan kepada seluruh perangkat birokrat perencana dan dinas-dinas teknis terkait di pemerintahan daerah tingkat II sebagai daerah dimana infrastruktur tersebut dibangun. Dengan paradigma berpikir sistem akan mengikis ego sektoral terkait infrastruktur. Pemecahan permasalahan menjadi lebih komprehensif dan menyangkut seluruh aspek terkait dengan keberadaan infrastruktur sehingga pemanfaatan dari sebuah infrastruktur dapat lebih dioptimalkan. Berpikir sistem akan memberikan kesadaran akan pentingnya bekerja atas dasar team work karena dengan bekerja team work hasil pemikiran bersama dari berbagai sudut pandang sektor akan lebih dapat memberikan gambaran permasalahan infrastruktur secara menyeluruh.

Pemerintah daerah perlu menginisiasi kegiatan penguatan kapasitas birokrat perencana dan dinas-dinas terkait agar setiap birokrat mempunyai landasan berpikir sistem didalam bekerja. Pemerintah daerah tingkat II tidak bisa bekerja sendiri dalam usaha peningkatan kualitas sumberdaya manusianya. Pemerintah daerah perlu menyapa perguruan tinggi terdekat yang mempunyai berbagai keahlian dan mengkontribusikan keahlian-keahlian tersebut kepada para birokrat perencana dan dinas-dinas teknis terkait. Selain itu pemerintah daerah tingkat II perlu juga menggandeng pemerintah pusat untuk memberikan bantuan tenaga ahlinya tekait dengan evaluasi pasca pembangunan infrastruktur.

\section{UCAPAN TERIMA KASIH}

Ucapan terima kasih disampaikan kepada LPPM - ITS atas pendanaan melalui hibah lokal ITS 2020 (ABDIMAS) Tipe Pengabdian Masyarakat Tahun Anggaran 2020.

\section{DAFTAR PUSTAKA}

American Association of State Highway and Transportation Officials, (2009). Transportation and Sustainability Best Practice Background: Prepared by $\mathrm{CH} 2 \mathrm{M}$ HILL and Good Company for Center for Environmental Excellence by AASHTO Transportation and Sustainability Peer Exchange May 27-29, 2009, Gallaudet University Kellog Center.

Blanchard, B., S., and Fabrycky W., J. (1998). System Engineering and Analysis. $3^{\text {nd }} \mathrm{Ed}$. Prentice Hall International Inc. USA. ISBN 0-13-095062-9

Excel, Nicolas Jacob., Rietveld, Piet. (2010). Perception of Public Transport Travel Time and Their Effect On elatihan ChoiceSet Among Car Drivers. Journal of Transport and Land Used.

Jackson, M. C., (2002). Systems Approaches to Management, Kluwer Academic Publishers, USA. eBook ISBN 0-30647465-4.

Mingers, J. (2006). Realising Systems Thingkings: Knowledge and Action in Management Science. $2^{\text {nd }}$ Ed. Springer Science+Business Media inc., USA.

Muhammadi, A.E.S.B., (2001). Systems Dynamic Analysis: Environmental, Social, Economic, Management. Jakarta: UMJ Press

Wang, J., Lu, H., \& Peng, H. (2008). System dynamics model of urban transportation system and its application. Journal of Transportation Systems Engineering and Information Technology, 8(3), 83-89. 